Guilleminault $\mathrm{C}$, ed. Sleep and its disorders in children. New York: Raven Press, 1987: 29-41.

3 Critchley M, Hoffman HL. The syndrome of periodic somnolence and morbid hunger (Kleine-Levin syndrome). BMF 1942; i: 137-9.

4 Diagnostic Classification Steering Committee, Thorpy MJ, chairman. International classification of sleep disorders diagnostic and coding manual. Rochester: American Sleep Disorders Association, 1990: 43-6. 5 Billiard M, Cadilhac J. Les hypersomnies recurrentes. Rev

6 Will RG, Young JPR, Thomas DJ. Kleine-Levin syn- drome: report of two cases with onset of symptoms precipitated by head trauma. Br f Psychiatry 1988; 152 410-2.

7 Merriam AE. Kleine-Levin syndrome following acute viral encephalitis. Biol Psychiatry 1986; 21: 1301-4.

8 Ferguson BG. Kleine-Levin syndrome: a case report. f Child Psychol Psychiatry 1986; 27: 275-8.

9 Gillberg C. Kleine-Levin syndrome: unrecognised diagnosis in adolescent psychiatry $7 \mathrm{Am}$ Acad Child Adolesc Psychiatry 1987; 26: 793-4.

10 Goldberg MA. The treatment of Kleine-Levin syndrome with lithium. Can $\mathcal{f}$ Psychiatry 1983; 28: 491-3.

\title{
Down's syndrome
}

Three papers in the July 1994 issue of Developmental Medicine and Child Neurology (1994; 36: 576-85, 586-93, and 594-600) describe problems encountered by children with Down's syndrome. It has been estimated that between 0.6 and $13 \%$ of children with Down's syndrome also have infantile spasms. Seventeen children with this combination were identified in Boston, Massachusetts (Carl E Stafstrom and Richard J Konkol: 576-85). In general the addition of infantile spasms to Down's syndrome seemed less disastrous than might have been expected. The prognosis for control of seizures was quite good and developmental progress on the whole remained within the range expected in Down's syndrome, although some children who regressed with the onset of infantile spasms remained developmentally impaired.

Workers in Newfoundland (Mary L Courage and colleagues: 586-93) measured visual acuity in 51 infants and children with Down's syndrome. They found a significant reduction in visual acuity and delayed development of visual acuity especially after the age of 6 months.

In Chicago 77 unselected children at a Down's syndrome clinic were examined first by a developmental paediatrician and then by a paediatric ophthalmologist (Nancy J Roizen and colleagues: 594-600). The paediatrician found an ophthalmic abnormality in 31 children and the ophthalmologist confirmed these and found an abnormality in a further 15 . Overall $61 \%$ of children had an ophthalmic abnormality, $38 \%$ of the infants and $80 \%$ of those aged 5 to 12 years. The most common disorders were refractive errors, squint, and nystagmus. These authors conclude that all children with Down's syndrome should be examined by a paediatric ophthalmologist before the age of 6 months and regularly after that. 